OPEN ACCESS

Edited by:

Timothy F. Burns,

University of Pittsburgh, United States

Reviewed by:

Herbert Levine,

Rice University, United States

Mohit Kumar Jolly,

Indian Institute of Science (IISC), India

${ }^{*}$ Correspondence:

Hai-Ning Chen hnchen@scu.edu.cn

Zong-Guang Zhou

zhou767@scu.edu.cn

Specialty section:

This article was submitted to

Cancer Molecular

Targets and Therapeutics,

a section of the journal

Frontiers in Oncology

Received: 23 January 2021

Accepted: 09 April 2021

Published: 29 April 2021

Citation:

Liu Q-L, Luo M, Huang C, Chen H-N and Zhou Z-G (2021) Epigenetic Regulation of Epithelial to Mesenchymal Transition in the Cancer Metastatic Cascade: Implications for Cancer Therapy.

Front. Oncol. 11:657546. doi: 10.3389/fonc.2021.657546

\section{Epigenetic Regulation of Epithelial to Mesenchymal Transition in the Cancer Metastatic Cascade: Implications for Cancer Therapy}

\author{
Qiu-Luo Liu ${ }^{1}$, Maochao Luo $^{2}$, Canhua Huang ${ }^{2}$, Hai-Ning Chen ${ }^{1 *}$ and Zong-Guang Zhou ${ }^{1 *}$ \\ 1 Department of Gastrointestinal Surgery, State Key Laboratory of Biotherapy and Cancer Center, West China Hospital, \\ Sichuan University, Collaborative Innovation Center for Biotherapy, Chengdu, China, ${ }^{2}$ Department of Biotherapy, State Key \\ Laboratory of Biotherapy and Cancer Center, West China Hospital, and West China School of Basic Medical Sciences \& \\ Forensic Medicine, Sichuan University, and Collaborative Innovation Center for Biotherapy, Chengdu, China
}

Metastasis is the end stage of cancer progression and the direct cause of most cancerrelated deaths. The spreading of cancer cells from the primary site to distant organs is a multistep process known as the metastatic cascade, including local invasion, intravasation, survival in the circulation, extravasation, and colonization. Each of these steps is driven by the acquisition of genetic and/or epigenetic alterations within cancer cells, leading to subsequent transformation of metastatic cells. Epithelial-mesenchymal transition (EMT), a cellular process mediating the conversion of cell from epithelial to mesenchymal phenotype, and its reverse transformation, termed mesenchymal-epithelial transition (MET), together endow metastatic cells with traits needed to generate overt metastases in different scenarios. The dynamic shift between these two phenotypes and their transitional state, termed partial EMT, emphasizes the plasticity of EMT. Recent advances attributed this plasticity to epigenetic regulation, which has implications for the therapeutic targeting of cancer metastasis. In this review, we will discuss the association between epigenetic events and the multifaceted nature of EMT, which may provide insights into the steps of the cancer metastatic cascade.

Keywords: epithelial to mesenchymal transition, epithelial-mesenchymal plasticity, epigenetics, metastatic cascade, cancer therapy

\section{INTRODUCTION}

Metastasis is a complex process by which tumor cells spread to distant sites and is the leading cause of mortality among patients with cancer (1). To successfully spawn a metastasis, cancer cells need to adopt invasive properties to migrate locally, disseminate and survive in the circulation, and acquire initiating capabilities to form colonization at distant organs, which is termed as the metastatic cascade (2). During metastasis, cancer cells have been proposed to hijack the epithelialmesenchymal transition (EMT), a transient change of cell phenotype from the epithelial to mesenchymal state initially characterized by embryonic development (3). 
Cancer cells with the epithelial phenotype display apicalbasal polarity, specialized intercellular junctions, and contact with the basement membrane (3). These differentiated cells are shown to be in the state of proliferation and drug sensitivity (4). After EMT initiation, cancer cells may dedifferentiate into the mesenchymal state, leading to increased motility and development of an invasive phenotype (5). Cancer cells with the mesenchymal state have stem cell-like characteristics and are more resistant to treatment (4). However, this subtype of cells exhibits low levels of proliferation (6). In other words, the mesenchymal cells are predominant in the context of dissociation from the primary tumor, whereas cells in the epithelial state are the superior subpopulation during the outgrowth of both primary and secondary tumors.

The involvement of EMT in metastasis and even the very existence of this process has been a subject of debate for a long time. This is in large part due to the technical challenge and poor understanding of EMT plasticity. The detection of EMT in vivo is difficult owing to the transient and reversible nature of this process and tumor cells that have undergone EMT are indiscernible from stromal cells in the tumor microenvironment (7). Despite these challenges, recent advances in lineage marking and intravital realtime visualization techniques have enabled direct characterization of EMT during cancer progression (8-10).

Nevertheless, a large number of studies forcing downregulation or overexpression of key EMT-TFs have reported contradicting roles of EMT in forming metastasis $(4,6)$. Of note, there were two studies employing the same pancreatic carcinoma model. While one study indicated that EMT program suppression by genetically knock out of SNAI1 or TWIST failed to alter the emergence of metastasis (11), the other one showed that EMT suppression by ZEB1 depletion significantly repressed the spread to distant organs (12). An extrapolation can be made that forcibly fixing cells in either a mesenchymal or epithelial state may lead to the loss of phenotypic plasticity, which in turn results in the failure of metastatic outgrowth. Besides, evidence from the past few years has demonstrated that tumor cells rarely undergo a full EMT, instead, most of them proceed to a state with certain mesenchymal characteristics as well as some epithelial qualities, namely partial EMT $(13,14)$. This adoption of hybrid epithelial/mesenchymal features, together with the ability to move along the epithelial/ mesenchymal spectrum has now been termed as epithelialmesenchymal plasticity (EMP) (15).

According to the previous understanding, cancer cells that have undergone EMT were fixed in a specific state. This notion is contrasted by recent evidences on the phenotypic reversal of EMT after arriving at distant sites, where contextual signals originating from the microenvironment induce a mesenchymal-epithelial transition (MET) program to drive disseminated cells to revert to the epithelial state $(10,16,17)$. The dynamic process of EMT and MET endows tumor cells with multiple qualities that are required to complete all the steps of metastatic cascade (18). The global reprogramming of gene expression involved in EMP, combined with non-genetic heterogeneity displayed by clonal populations, implying that reversible epigenetic regulation rather than permanent genetic mutations as potential molecular mechanisms underlying this process $(4,19)$. Emerging evidence has revealed the functional roles of epigenetic mechanisms including histone modification, DNA methylation, and noncoding RNA in EMT/EMP that facilitate cancer metastasis (20).

In this review, we will discuss the epigenetic changes involved in the regulation of EMT in metastatic cascade and emphasize herein the difficulties and controversies of epigenetic therapies that target EMT for cancer treatment, with the aim to provide a perspective for future research.

\section{EPIGENETIC REGULATION OF EMT IN THE METASTATIC CASCADE}

\section{EMT Initiation During Local Invasion}

For local migration, epithelial cells must acquire traits that favor detachment from the primary sites and penetration into the adjacent parenchyma (Figure 1). In the primary tumor, epithelial cell junctions including tight junctions, adherens junctions, desmosomes, gap junctions, and hemidesmosomes are formed to maintain cell-cell and cell-matrix contacts. Upon EMT, cell-cell junctions (mainly E-cadherin) are destabilized to allow cell detachment, while cell-matrix contacts mediated by integrins are also destructed and switched to specific patterns that promote cell migration (21). EMT activation also leads to upregulation of extracellular proteases such as matrix metalloproteinases (MMPs) and serine proteinases, which not only degrades extracellular matrix (ECM) but also cleaves E-cadherin and releases bioactive fragments that promote cell motility (2). Furthermore, EMT program results in actin cytoskeleton remodeling, forming actinrich protrusions on the plasma membrane called lamellipodia, filopodia, and invadopodia, in which invadopodia plays a key role in cell invasion as it may also degrade ECM (3).

The initiation of EMT program is considered responsive to specific environmental stimuli during cancer development and progression (7) (Figure 2). Soluble growth factors including transforming growth factor-beta (TGF- $\beta$ ), epidermal growth factor (EGF), fibroblast growth factor (FGF), hepatocyte growth factor (HGF) secreted by stromal cells such as cancer-associated fibroblast, tumor-associated macrophage and neutrophil play a critical role in activating EMT in cancer cells (18). Subsequently, activated signaling such as TGF $\beta$-SMAD3, WNT- $\beta$ catenin, and Notch induces the expression of EMT-related transcription factors (EMT-TFs) such as Zeb1, Zeb2, Snail, Slug, and Twist. These EMTTFs act in concert to downregulate the expression of epithelial markers such as E-cadherin, claudins, and occludin, and concurrently upregulate the expression of mesenchymal markers such as N-cadherin, vimentin, and fibronectin (3). Mechanistically, these EMT-TFs are regulated at a transcriptional level by DNA methylation, histone modifications, and RNA-mediated epigenetic regulation $(6,22)$ (Figure 3). For example, in breast cancer, the GATA3/G9A/NuRD(MTA3) complex inhibited the expression of Zeb2 by catalyzing $\mathrm{H} 3 \mathrm{~K} 9$ methylation of ZEB2 promoter (23), while Snail suppressed the expression of E-cadherin by recruiting histone lysine-specific demethylase 1 (LSD1) to $\mathrm{CDH1}$ promoter (24). In 


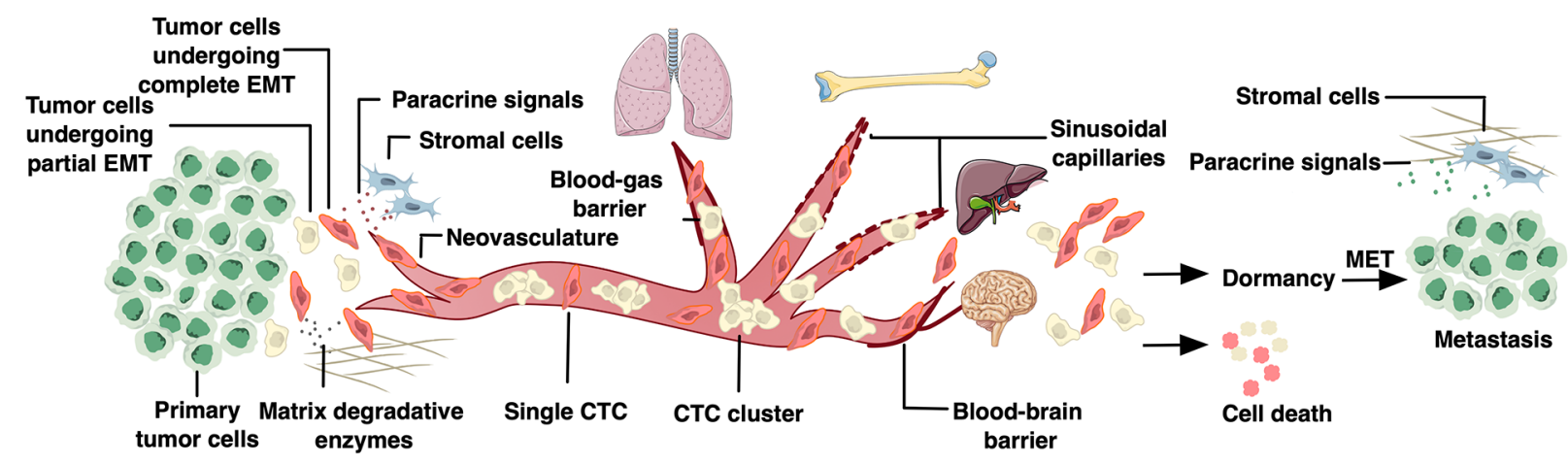

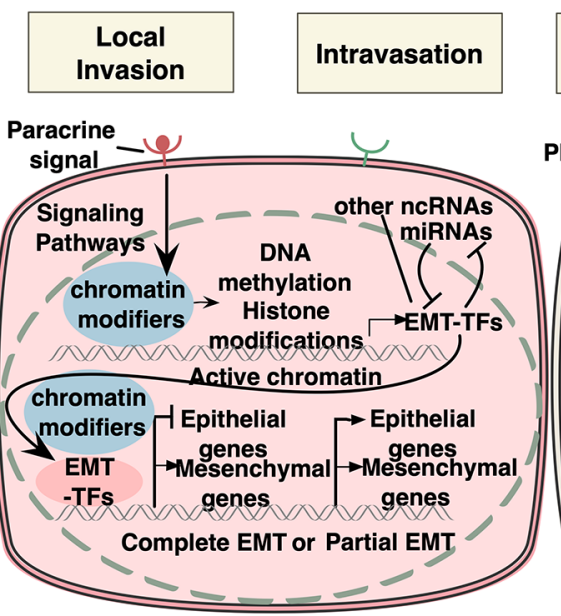

EMT initiation

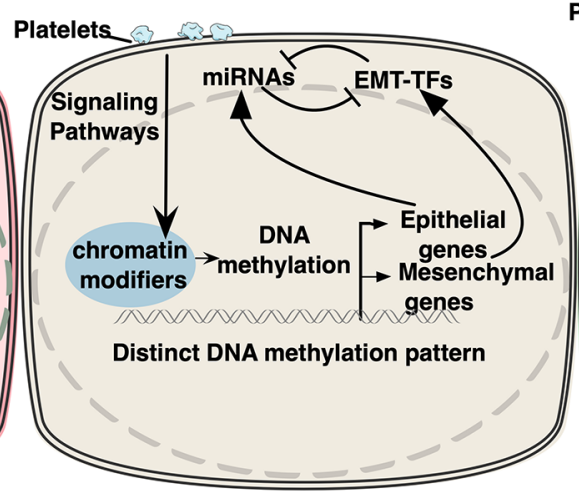

EMT maintenance

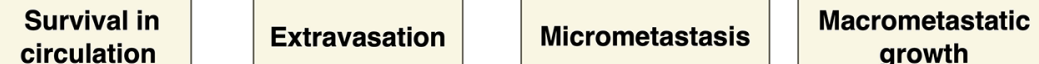
growth

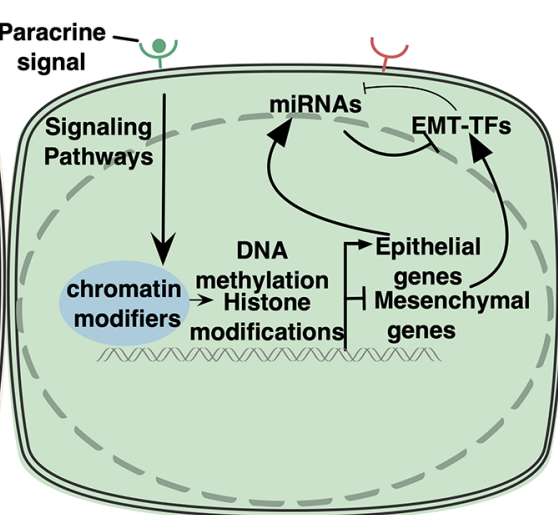

EMT reversal

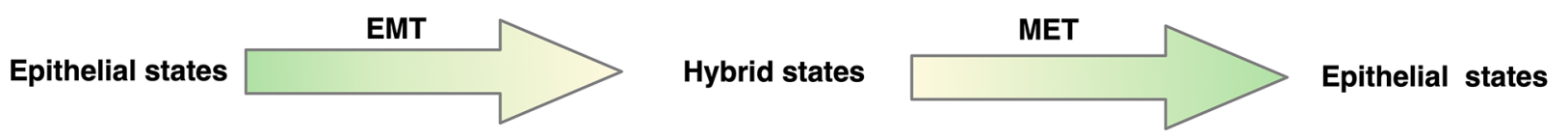

FIGURE 1 | Epigenetic regulation of epithelial to mesenchymal transition in cancer metastatic cascade. In the primary tumor, for local migration, epithelial tumor cells initiate EMT program by activating signaling pathways responsive to specific environmental stimuli. As a result, EMT-related transcription factors (EMT-TFs) are induced, whose expression can be regulated by DNA methylation, histone modifications, and RNA-mediated epigenetic regulation. Next, EMT-TFs collaborate with various epigenetic proteins to regulate the expression of downstream EMT effectors. It is assumed that tumor cells undergo partial EMT instead of complete EMT to improve their metastatic ability. After local migration, tumor cells disseminate into the circulation, known as circulating tumor cells (CTCs). CTCs interact with platelets through different cell surface receptors and ligands, by which they sustain EMT via platelet-derived TGF $\beta$ signals in the absence of stroma-derived signaling cues that initiated EMT in the microenvironment of the primary lesion. CTC clusters and single CTCs have been demonstrated to exhibit distinct DNA methylation patterns of EMT-associated genes. In addition, members of miR-200 family have been acknowledged as key regulators of EMT maintenance in CTCs by forming doublenegative feedback loops with EMT TFs, in which they reciprocally repress each other's translation or transcription. The extravasation mechanisms of CTCs vary widely depending on the flow direction and organ-specific vascular structure. Upon reaching the distant sites, the vast majority of carcinoma cells will not survive, while a small minority persist in a quiescence state as dormant cancer cells until reinitiate growth and form colonization. It is proposed that invasive cells need to undergo MET to acquire the capability of macrometastatic growth. MET is mainly triggered and regulated by contextual signals from microenvironment or due to the absence of EMT-inducing signals from the primary tumor microenvironment, resulting in downregulation of several EMT-TFs. The negative feedback loops consisting of pairs of miRNAs and EMT-TFs are also considered the driving force underpinning this state reversibility. Both EMT-TFs and micro RNAs in these loops have also been shown to be elaborately regulated by epigenetic mechanisms including DNA methylation and histone modifications.

addition, other chromatin modifiers, including DNA methyltransferases (DNMTs) (25), histone methyltransferases (HTMs) (26), histone acetyltransferases (HATs) and histone deacetylases (HDACs) $(27,28)$, chromatin-remodeling complexes such as PRC1 (29) and SWI/SNF (30), have been implicated in the interplay with EMT-TFs, functioning as either transcriptional suppressor or activators of EMT-TFs as well as downstream EMT-associated genes in multiple cancer types. Furthermore, epigenetic profiling has revealed genome-scale reprogramming during EMT, including alterations in DNA methylation in ovarian cancer cells (31) and an increase in H3K4Me3 and $\mathrm{H} 3 \mathrm{~K} 36 \mathrm{Me} 3$ while a reduction in $\mathrm{H} 3 \mathrm{~K} 9 \mathrm{Me} 2$ in mouse hepatocytes (32). Recent research discovered a more unifying mechanism underlying EMT in pancreatic cancer cells, in which a genomewide increase in $\mathrm{H} 3 \mathrm{~K} 36 \mathrm{me} 2$ modulated the expression of nearly all master EMT-TFs (33). 


\section{Stromal cells Cancer-associated fibroblast Tumor-associated macrophage Neutrophil}

\section{Microenvironment} Hypoxia

ECM

Hypermetabolism

\section{Platelet-derived TGF- $\beta$ signals}

Stromal cells

Cancer-associated fibroblast

Endothelial cells

Myeloid progenitor cells

\section{Soluble Growth factors} Transforming growth factor-beta (TGF- $\beta$ )

Epidermal growth factor(EGF)

Fibroblast growth factor(FGF)

Hepatocyte growth factor(HGF)

\section{Primary tumor}

CTCs
Metastasis

FIGURE 2 | Environmental stimuli of EMT and MET. Specific environmental stimuli lead to the initiation of EMT program during cancer development and progression. In the microenvironment of the primary lesion, soluble growth factors including transforming growth factor beta (TGF- $\beta$ ), epidermal growth factor (EGF), fibroblast growth factor (FGF), hepatocyte growth factor (HGF) secreted by stromal cells such as cancer-associated fibroblast, tumor-associated macrophage, and neutrophil activate several signaling pathways in cancer cells. These signaling pathways then regulate the EMT-related transcription factors (EMT-TFs) through epigenetic mechanisms. Hypoxic stress and altered metabolism from the microenvironment are also stimuli of EMT. For CTCs, in the absence of stroma-derived signaling cues that initiated EMT, platelet-derived TGF- $\beta$ signals serve as the stimuli to sustain EMT. Although the external stimuli of MET are currently largely unknown, it has been proposed that MET can be triggered by stromal cells from the microenvironment including cancer-associated fibroblast, endothelial cells, and myeloid progenitor cells, or passively result from the absence of EMT-inducing signals from the primary tumor microenvironment.

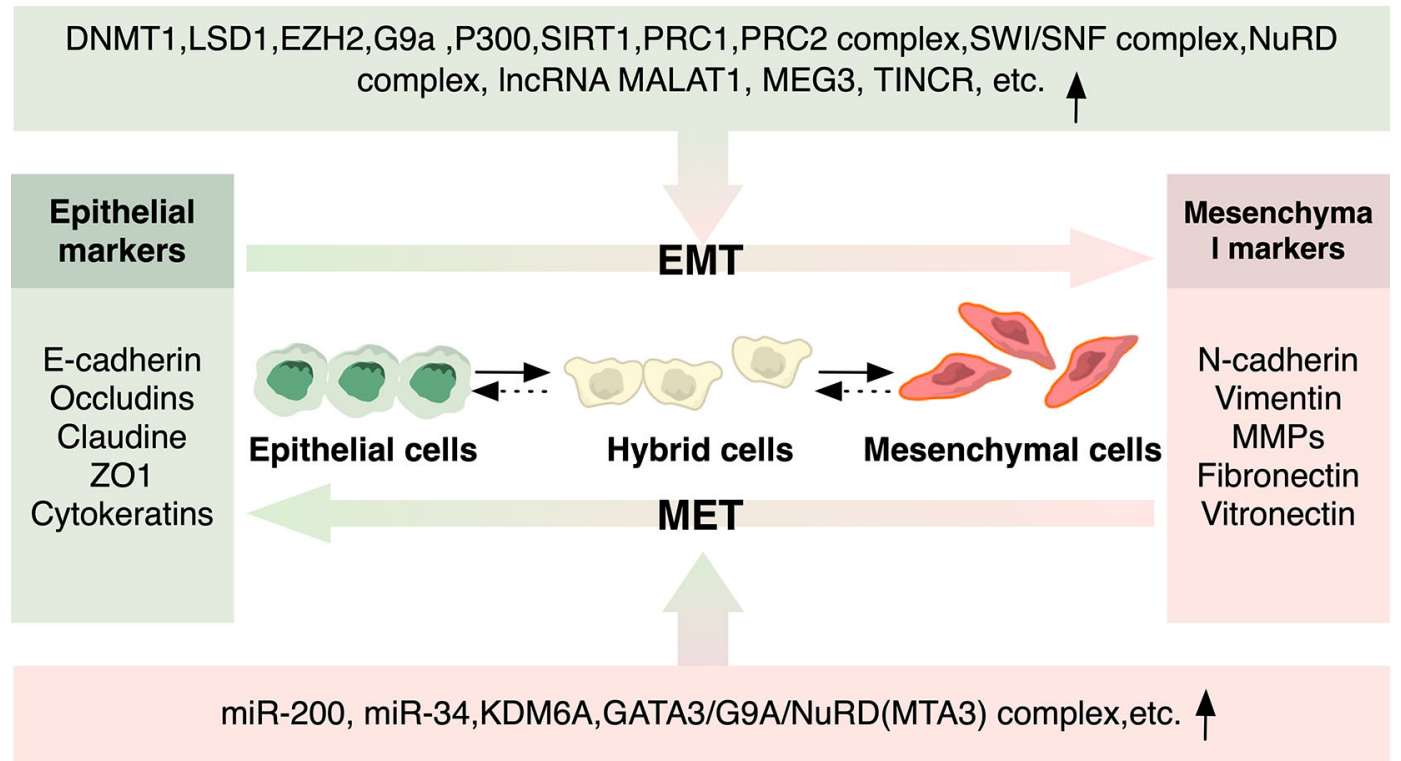

FIGURE 3 | Epigenetic Regulators of EMT and MET. Epigenetic modulators involved in histone modification, DNA methylation, and non-coding RNA in EMT/MET that regulate cancer metastasis are depicted. Epigenetic regulators can either be recruited by EMT-TFs to regulate the expression of downstream EMT-associated genes, or they can directly function as either transcriptional suppressor or activators of EMT-TFs as well as downstream EMT-associated genes. 
Notably, epigenetic mechanism was also shown to be involved in partial EMT, where inactive EZH2 in FAT1-mutated skin squamous cell carcinoma and lung cancer cells reduced the inhibitory action of $\mathrm{H} 3 \mathrm{~K} 27 \mathrm{me} 3$ on the promoter of $S O X 2$, contributing to the epithelial phenotype of cancer cells in hybrid EMT state (34). Additionally, RNA-mediated epigenetic regulation also has an impact on EMT program. For instance, members of miR-200 and miR-34 family were acknowledged as key regulators of EMT in a variety of cancers by forming doublenegative feedback loops with Zeb and Snail family, in which they reciprocally repressed each other's translation or transcription $(35,36)$. However, although frequently regarded as EMT inhibitors, the expression level of miR-200 family can be elevated in several types of cancer, in which its overexpression is correlated with poor clinical outcome $(37,38)$.

\section{EMT Maintenance During Intravasation, Survival in Circulation and Extravasation Intravasation and Survival in Circulation}

After dissociating from the primary tumor, tumor cells must acquire the ability of transendothelial migration to get access to the systemic circulation. EMT promotes intravasation via orchestrating several biological processes including angiogenesis and disruption of the endothelial integrity (Figure 1). During metastasis, abnormal neovasculature with high density and hyperpermeability lead to efficient access to the bloodstream. In breast cancer, EMT contributes to the form of a conduit for metastatic dissemination as evidenced by upregulated angiogenesis genes including VEGFA and higher microvascular density displayed by both primary and metastatic tumors upon EMT (39). In addition to angiogenesis, EMT is also required during intravasation. For instance, in breast cancer, Snail1 induced MT1-MMP and MT2-MMP and enhanced disruption of the basement membrane (40). Although the specific mechanism by which EMT-mediated MMPs regulate intravasation has not been fully elucidated, MMPs-dependent intravasation has already been experimentally addressed in other studies (40-42), suggesting the potential role for EMT in facilitating transendothelial migration.

Tumor cells disseminating into the circulation, which are termed as circulating tumor cells (CTCs), may form cell clusters by associating with each other or other cells such as platelets to survive under the immune system and shear stress (Figure 1). Results from previous studies demonstrated that CTCs exhibit various states, including mesenchymal, epithelial, and hybrid states. Along this line, it has been proposed that a complete transition to mesenchymal states is associated with single cell migration, while the hybrid states with transient cell-cell junctions resulting from partial EMT facilitate collective migration (43). Of note, CTC clusters in hybrid state are shown to have up to 50 -fold enhanced dissemination potential than single CTCs in complete mesenchymal phenotype (44). This notion was further favored by a recent study showing that a complete EMT in breast cancer cells caused by loss of E-cadherin led to excessive oxidative stress and subsequently cell death, culminating in the decreased number of CTCs and reduced distant colonization (45).

However, it remains controversial which state (primarily epithelial with a moderate mesenchymal trait or primarily mesenchymal with moderate epithelial traits) plays a more crucial role in metastasis. Previously, it was revealed in human breast cancer specimens that elevated levels of mesenchymal CTCs during metastasis are correlated with acquired drugresistance and poor prognosis (46). This was contrasted by recent studies showing that Lgr5, a mesenchymal marker (47), was negative in the majority of CRC CTCs (48). It was also reported that in breast cancer, CTCs with a dominating epithelial phenotype and modest mesenchymal features had the strongest metastatic potential among all identified phenotypes, and the proportion of epithelial CTCs was significantly related to distant metastasis and poor prognosis in patients (49). Overall, the determinants of metastasis occurrence may be the acquisition of features that make CTCs adaptive and viable, rather than certain fixed types of phenotypes.

\section{Extravasation}

During extravasation, CTCs lodge in narrow microvasculatures and protrude through the endothelial barrier at distant anatomical sites. EMT has been identified to facilitate CTCs extravasation through the opening of the endothelial barrier and alterations in CTCs shape and motility. In a drosophila CRC model, in vivo imaging visually demonstrated that overexpressing Snail in tumor cells triggered the breakdown and remodeling of the basal lamina to facilitate transendothelial migration (50). A previous study in zebrafish model also provided evidence suggesting that Twist upregulation in extravasating breast tumor cells induced reorganization of intercellular junctions of endothelial cells (51). What's more, a recent study indicated that EMT activation of breast cancer cells orchestrated cytoskeleton rearrangement to endow cancer cells with polarized and aggressive morphology, thereby enhancing extravasation to form lung metastases (52).

The maintenance of EMT is considered more important as compared to the initiation of EMT, as the stroma-derived signaling that activates EMT in the microenvironment of primary lesion is absent throughout the vast majority of metastatic cascade. The epigenetic regulation of members of miR-200 family was acknowledged as key process of EMT maintenance in a variety of cancers $(6,22,36,53)$. A recent study in breast cancer using mathematical methods revealed the dynamic regulation of a negative feedback loop miR200s/Zebs, via which a short time exposure to stimuli was sufficient to sustain EMT for a long time (53). Moreover, data from single-cell resolution assay disclosed the epigenetic regulation of $m i R-200$ gene in CTCs. By focusing on the promoter methylation of $m i R-200 c / 141, m i R-200 b / a / 429$, and $\mathrm{CDH} 1$ in CTCs isolated from patients with metastatic breast and prostate cancer, conspicuous heterogeneous methylation patterns were observed not only among patients, but also within the same individual. The observed heterogeneity supported the notion that CTCs reside in the dynamic transition of epithelial and mesenchymal axis (54). Besides, altered levels of miRNAs such as miR-16, miR-21, miR-31, and miR-210, which were identified 
relevant to EMT, were also observed in CTCs across a number of types of cancer (55).

In addition, it is believed that CTCs may interact with platelets through different cell surface receptors and ligands to sustain EMT via platelet-derived TGF- $\beta$ signals (56) (Figure 2). Emerging evidence suggested that the downstream mechanism of this signal may involve epigenetic alterations. A recent study analyzed the methylation landscape in CTCs from patients with breast cancer and xenografts. Compared with single CTCs, CTC clusters showed higher hypomethylation for transcription factors binding sites, involving genes related to stemness, proliferation as well as cell adhesion which were also implicated in EMT (5759 ) and this pattern was associated with poorer clinical outcomes (60). The authors concluded that the capacity of CTCs to spread in the circulation functions as the force to shape the DNA methylation pattern (60).

Recently, a hypothesis was put forward stating that EMT involved two tiers of control. While the acute phase was regulated by instant transcriptional regulation of EMT-TFs, a stable phase was enhanced by the global H3K36me2 levels, suggesting another possible epigenetic mechanism harnessed by cancer cells to maintain EMT (33). Overall, despite the technical challenges of investigating CTCs, the recent advance in single-cell sequencing has brought opportunities to study the epigenetic regulation of them, which may provide further insights into the dynamic molecular changes of EMT (61).

\section{EMT Reversal During Dormancy and Colonization}

Upon reaching the distant sites, cancer cells need to adapt to the foreign microenvironment. While the vast majority of cancer cells will not survive, a small minority persist in a quiescence state as dormant cancer cells until reinitiate growth and form a colonization (Figure 1) Therefore, colonization is considered the major rate-limiting step in the metastasis cascade (2). EMT has been implicated in the regulation of dormancy by triggering cell cycle arrest. A substantial amount of evidences have shown that invasive cancer cells that have undergone EMT are in a state of low proliferation, that is, EMT-associated growth arrest (4). The underlying molecular mechanism involves the induction of cell cycle arrest by EMT TFs through directly suppressing cyclin expressions or inhibiting the expression of proliferating cell nuclear antigen (PCNA) $(62,63)$. While the mesenchymal state can exert proliferation inhibition on cells, the epithelial state allows growth. Clinical observation showed that most metastases across various types of carcinomas are highly differentiated (4). These clues lead to the proposition of the term MET, which assumes that invasive cells must re-differentiate to acquire the capacity of macrometastatic growth. Recent studies have demonstrated that MET is mainly triggered by contextual signals from microenvironment (Figure 2) $(6,64-66)$ as the absence of EMT-inducing signals from primary tumor microenvironment has already occurred after the early stage of metastatic cascade.

Indeed, the role of MET in metastatic outgrowth has been confirmed in numerous studies $(10,67-69)$. For instance, in squamous cell carcinoma, inhibition of Twistl was required for MET to initiate tumor growth at a secondary site (68). In line with this notion, compelling evidence obtained in vivo has shown spontaneous interconversion between mesenchymal and epithelial phenotypes in primary tumors and metastases in breast and skin cancer, further reinforcing the existence and critical role of MET in reawakening proliferation $(9,10)$.

In addition to EMT maintenance, the negative feedback loops consist of pairs of miRNAs and EMT-TFs are also considered as the driving force underpinning the reversal of EMT. The most canonical feedback loops are miR-200-Zeb and miR-34-Snail (6, 22, 36, 53). Mathematical models analyzing the dynamics of EMT showed that these circuits resulted in epithelial states, mesenchymal states, or hybrid states. Once cells entered into an epithelial or mesenchymal state in response to environmental signals in the distant site, this state can be efficiently reinforced and self-stabled by feedback loops (70-72), ensuring phenotypic reversal. More importantly, compared with cells that directly switch to the extreme of the epithelial-mesenchymal axis, cells with an intermediated state can lower the threshold to initiate the epithelial or mesenchymal state, thus endowing partial EMT cells with higher plasticity (72).

Remarkably, both microRNAs and EMT markers in these tightly interconnected loops have also been shown to be elaborately regulated by epigenetic mechanisms encompassing DNA methylation and histone modification in different cancer types (22) (Figure 3). For example, in liver metastases of colorectal cancer, hypomethylation of $m i R-200 c$ and $m i R-141$ promoter regions led to reversal of epithelial markers (73). In breast cancer, it was identified that $\mathrm{H} 3 \mathrm{~K} 27$ me3-demethylase KDM6A-mediated bivalent chromatin state functioned as a regulator of a series of EMT/MET-associated bivalent genes. During EMT initiation, KDM6A was repressed, leading to transcriptional repression of epithelial genes, while during MET, the expression of KDM6A restored, enabling phenotypic reversal by reactivation of epithelial genes through $\mathrm{H} 3 \mathrm{~K} 27 \mathrm{me} 3$ removal (74). Thus, collectively, the process of colonization on secondary sites involves regulation of MET that orchestrates a range of epigenetic regulations of cancer cells to enable a dynamic state shift, conferring adaptability to survive in distinct environments of target organs.

Noteworthy, the seeding patterns and dormant time differ substantially across different cancer types and subtypes due to the organ tropisms of metastatic cells (75). Under the influence of the target organs microenvironment, even tumors of the same type may exhibit diverse malignant behaviors due to differences among tumor subtypes. As an example, $\mathrm{ER}^{+}$breast cancer often remains inactive in bone for decades, whereas triple-negative breast cancers tend to develop metastatic outbreaks in the lung within a short period of time (76). This heterogeneity is presumably due to distinct interactions between dormant malignant cells and the microenvironment, and the resulting context-dependent EMT-related epigenetic regulation. As the organ-specific patterns of metastatic colonization are being gradually unveiled recently, EMT-associated epigenetics in this process warrants further investigation. 


\section{THERAPIES TARGETING EMT VIA EPIGENETIC MODIFICATION}

\section{Targeting EMT in Different Stages of Metastasis}

Owing to the reversible nature of epigenetic modification, it will be of prime interest to target epigenetic mechanisms to manipulate different cancer cell states (Figure 4). By far, major EMT-associated therapies aim at reverting or preventing EMT through targeting different aspects of this process, involving modulation of upstream pathways such as WNT, NOTCH, and TGF- $\beta$ signaling (77), manipulation of stromal cells in the microenvironment such as tumor-associated macrophages, neutrophils and fibroblasts, employment of EMT-repressing miRNAs $(78,79)$, and direct inhibition of EMT-TFs via CRISPR-Cas9 (18, 80). As discussed above, the EMTepigenetic network has been supported by a myriad of studies on the interactions between EMT-TFs and epigenetic regulators (22). Accordingly, approaches generally block EMT via epigenetic drugs targeting EMT-TFs, including DNMTs inhibitors, histone demethylase (HDMs) inhibitors, histone methyltransferases (HMTs) inhibitors and HDACs inhibitors.

Since piles of experiments have been done to prove the validity of epigenetic drugs for EMT in experimental models, these agents are being evaluated by or have gone through clinical trials, although the role of EMT is not specifically targeted and the involvement of EMT inhibition remains unknown (80-82). For instance, nucleoside analogs can inhibit the activity of DNMT1, resulting in hypomethylation, re-activation of the tumor suppressor gene, and EMT inhibition in vitro. As the DNMT1 inhibitors 5-aza-2'-deoxycytidine (decitabine) and 5azacytdine have already been approved by FDA for treating acute myeloid leukemia and myelodysplastic syndromes, a clinical trial is underway to evaluate Aza-TdC for patients with advanced solid tumors (NCT03366116). A series of HDMs inhibitors and HMT inhibitors involving LSD1 inhibitor SP-2577 (Seclidemstat) (NCT03895684), EZH2 inhibitor CPI-1205 (NCT03525795), Tazemetostat (NCT01897571) are in trials against multiple cancer types. Moreover, many HDAC inhibitors such as Vorinostat, Tefinostat mocetinostat, and Panobinostat are also being extensively tested. Furthermore, as miRNAs have displayed critical roles in the regulation of EMT, the development of miRNA-based approaches has a promising potential. Progress has been made employing miRNAs in combination with multiple cytotoxic therapies, efficiently sensitize resistant cancer cells to chemotherapy in prostate cancer, pancreatic cancer and breast cancer (83-85).

Recently, treatments targeting CTCs in breast cancer were emerging as exemplified by ouabain and digitoxin, which have been approved by FDA as $\mathrm{Na}^{+} / \mathrm{K}^{+}$-ATPase inhibitors and were identified to dissociate CTC clusters that harbored a distinct DNA methylation pattern (60). Besides, it is noteworthy that while in most cases the inhibition of HDAC or HMTs resulted in repression of EMT and tumor growth, in some contradictory studies it showed precisely the opposite effect, again highlighting the context-dependent behaviors of epigenetic-regulated EMT networks and implying their possible role as MET blockers at the late stages of metastasis (86-88).

As discussed above, the H3K27me3-demethylase KDM6A, a bivalent chromatin regulator, served as the underlying mechanism of dynamic and reversible nature of EMT and MET in breast cancer cells, indicating that KDM6A may be a potential target to block the onset of MET. Indeed, treatment of KDM6A inhibitor GSK-J4 can repress various MET-associated genes in breast cancer cells (74). Furthermore, a recent study in pancreatic cancer revealed a unifying mechanism where a genome-wide change in H3K36me2 drove EMT and MET along the epithelial-mesenchymal spectrum. In this study, depletion of KDM2A, a histone demethylase that serves as the eraser of H3K36me2, locked tumor cells in a mesenchymal state and prevented MET, resulting in poor colonization of pancreatic cancer cells in the lung (33). Accordingly, it can be inferred that histone methyltransferases and demethylases that preferentially target $\mathrm{H} 3 \mathrm{~K} 36 \mathrm{me} 2$ are potential targets for pharmacologically inhibition of MET at the end stage of tumor metastasis. Indeed, various epigenetic enzymes that target $\mathrm{H} 3 \mathrm{~K} 36 \mathrm{me} 2$ already have small molecules inhibitors, among which some are currently being evaluated in clinical trials for different cancers, albeit further studies are required to clarify their specific roles in MET and metastatic colonization. However, given the distinct roles played by MET in the primary and metastatic lesions, it is worth noting that the true impact of epigenetic inhibitors in solid tumors could be confounding, for this reason, clinical trials of these therapies should not take alterations in primary tumor growth as the only outcome being evaluated.

\section{Targeting Epithelial-Mesenchymal Plasticity}

As the states of cells undergoing EMT during metastasis cascade are found as a continuum across EMT spectrum, interventions can take advantage of this to disturb the transition which is required for metastatic seeding. Nevertheless, due to the currently limited ability to define whether there is a distant micrometastasis during the progression of cancer and the contradictory roles played by EMT across a series of scenarios, it is difficult to target the specific stage of cancer metastasis therapeutically, highlighting the risk of inappropriate intervention in EMT. More specifically, with the undetectable metastasis lesions, preventing the mesenchymal state may result in enhanced epithelial-associated colonization. On the contrary, repressing the epithelial state may promote the disassociation of cancer cells from primary tumor, underscoring the requirement for context-specific therapeutic modalities for primary site and metastatic lesion (18). Distinct from traditional systemic administration of chemotherapy drugs, recent advances in nanomedicine-which apply artificial nanomaterials with exceptional properties to pharmaceutical products-have held great promise to selective organ targeting drug delivery (89). As such, loading epigenetic drugs that target the specific states in the EMT spectrum within nanoparticles may contribute to the 


\begin{tabular}{|c|c|c|c|}
\hline \multirow[t]{2}{*}{ Status } & $\begin{array}{c}\text { Primary } \\
\text { tumor }\end{array}$ & 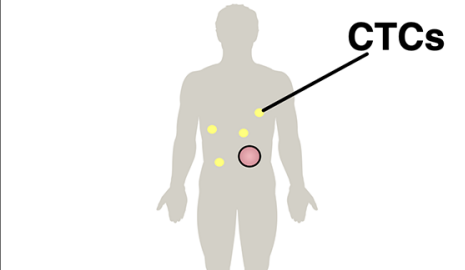 & $\int_{0}^{\text {Metastasis }}$ \\
\hline & Primary tumor & Circulating tumor cells & Metastasis \\
\hline Phenotype & $\begin{array}{l}\text { Epithelial } \\
\text { phenotype }\end{array}$ & \multicolumn{2}{|r|}{ MET $\begin{array}{c}\text { Epithelial } \\
\text { phenotype }\end{array}$} \\
\hline Focus & $\begin{array}{l}\text { Preventing the } \\
\text { mesenchymal state }\end{array}$ & $\begin{array}{l}\text { Disturbing the CTC } \\
\text { survival pathways }\end{array}$ & $\begin{array}{l}\text { Repressing the epithelial } \\
\text { state }\end{array}$ \\
\hline $\begin{array}{l}\text { Possible } \\
\text { Epigenetic } \\
\text { Treatment } \\
\text { Strategies }\end{array}$ & $\begin{array}{l}\text { - Chromatin modifiers that } \\
\text { inhibit EMT } \\
\text {-Upregulation of EMT- } \\
\text { suppressing miRNAs }\end{array}$ & $\begin{array}{l}\text { Dissociating CTC clusters } \\
\text { and remodeling DNA } \\
\text { methylation in CTCs }\end{array}$ & $\begin{array}{l}\text {-Chromatin modifiers that } \\
\text { promote EMT } \\
\text {-Downregulation of EMT- } \\
\text { suppressing miRNAs }\end{array}$ \\
\hline $\begin{array}{l}\text { Possible } \\
\text { Epigenetic } \\
\text { Agents }\end{array}$ & $\begin{array}{l}\text {-DNMTs inhibitors: } \\
\text { decitabine, 5-azacytdine, } \\
\text { MC3353, } \\
\text { epigallocatechin-3-gallate } \\
\text {-HDMs inhibitors: } \\
\text { Seclidemstat, } \\
\text { Tranylcypromine, } \\
\text { Pargyline } \\
\text { •HMTs inhibitors : }\end{array}$ & $\begin{array}{l}\mathrm{Na}^{+} / \mathrm{K}^{+} \text {-ATPase } \\
\text { inhibitors: ouabain and } \\
\text { digitoxin }\end{array}$ & $\begin{array}{l}\text {-HDACs inhibitors: } \\
\text { valproic acid, trichostatin } \\
\text { A } \\
\text { •HMTs inhibitor: GSK126 } \\
\text { •HDMs inhibitors: GSK- } \\
\text { J4, inhibitors of } \\
\text { H3K36me2 eraser } \\
\text {-Antisense RNAs of } \\
\text { miR-200 or -34 families ; }\end{array}$ \\
\hline $\begin{array}{l}\text { Conceptual } \\
\text { strategies } \\
\text { targeting } \\
\text { EMT } \\
\text { plasticity }\end{array}$ & \multicolumn{3}{|c|}{$\begin{array}{l}\text {-Fixing cells at a specific state within the EMT spectrum(eg, breaking the feedback } \\
\text { loop between ZEB and miR-200); } \\
\text {-Diverting dedifferentiated cancer cells to re-differentiate into other non-malignant } \\
\text { cell types (eg, inducing the trans-differentiation of EMT tumor cells into adipocytes) }\end{array}$} \\
\hline
\end{tabular}

FIGURE 4 | Possible therapeutic strategies targeting EMT plasticity via epigenetic modification. In different stages of metastasis, EMT and MET play contradictory roles, highlighting the need for context-specific therapeutic modalities for distinct disease status. As the interactions between EMT-TFs and epigenetic regulators have been widely revealed, targeting epigenetic mechanisms to manipulate EMT will have a promising therapeutic potential. Possible strategies include manipulation of miR-200s or miR-34 or chromatin modifiers that modulate EMT-TFs. Recently, treatments targeting CTCs are also emerging as exemplified by ouabain and digitoxin, which are FDA-approved $\mathrm{Na}^{+} / \mathrm{K}^{+}$-ATPase inhibitors and are identified to dissociate CTC clusters that harbor distinct DNA methylation pattern. Besides, various conceptual strategies targeting EMT plasticity are also proposed, with some of them are already proved effective in preclinical settings. 
organ-exclusive therapeutic effect for primary versus metastasis tumors.

Despite this dilemma, the plastic nature of EMT still offers an opportunity for therapeutic targeting. Conceptually, the interventions targeting EMP involves either fixing cells at a specific state in the EMT spectrum to restrict their plasticity or breaking the interconversion process by trans-differentiation (Figure 4). Stabilization of the hybrid state, or in other words, restricting bidirectional transitions of EMP, is supposed to overcome the aforementioned side effects $(4,18,80)$. Indeed, it was proposed by recent studies using subtle mathematical models that blocking the feedback loops integrated in the EMP network is likely to impair the metastatic potential of cancer cells (90). These feedback loops which enable the capability of cells to reversibly convert among a continuum of epithelial/ mesenchymal states were mathematically proved to be a driving force behind phenotypic plasticity (90). Proof-ofprinciple validation of this idea was shown experimentally, where breaking the feedback loop between Zeb and miR-200 by CRISPR/Cas9-based edition of Zeb1 binding sites in the promoter region of $m i R-200 s$ reduced the metastatic potential of breast cancer in vivo (53). Alternatively, diverting dedifferentiated cancer cells to re-differentiate into other nonmalignant cell types of the mesenchymal lineage could serve as a novel solution. Indeed, a seminal study exploiting EMP by inducing the trans-differentiation of EMT-state cancer cells into post-mitotic adipocytes has successfully reduced invasion and metastasis formation in a preclinical setting (91).

The above treatment options are built upon the notion that EMT/MET is reversible hence theoretically targetable. However, it should be noted that MET was not simply an antithesis of EMT, as different trajectories were used for cells that have undergone EMT(MET) to reverse back to the epithelial (mesenchymal) state $(92,93)$. Hence, the questions concerning the reversibility or irreversibility of EMT and/or MET have gained attention. Experimental studies have demonstrated that prolonged exposure to EMT stimulus such as TGF- $\beta$ would cause irreversible EMT, locking cells in the stable mesenchymal state $(53,94,95)$. So far, mechanisms regarding the concepts of when and if an EMT will be reversible have not been fully delineated.

Previously, a mathematical model integrating multiple feedback loops was proposed, in which the reversible transition from epithelial to hybrid phenotype was attributable to the miR34-Snail feedback loop, followed by the conversion to the mostly irreversible mesenchymal state that was driven by the miR-200Zeb1 feedback loop, moreover, the autocrine TGF- $\beta$-miR-200 feedback loop further stabilized the mesenchymal state to reinforce the irreversibility of EMT $(96,97)$. This model has been preliminarily validated in the human breast epithelial cell line MCF10A (98). Various attempts to characterize the underlying molecular mechanisms of the reversible or irreversible nature of EMT and/or MET have been made recently. These emerging studies have revealed global epigenetic alterations and identified major factors including Zeb1, RUNX2, GRHL, and CTCF involved in reversible or stabilized EMT/MET in multiple cell lines (69, 99-102). Besides, recent mathematical models proposed conceptually that epigenetic process may play a significant role in the irreversibility of EMT and MET, where epigenetic feedbackmediated suppression on miR-200 by Zeb1 led to the irreversibility of EMT, while epigenetic feedback-mediated suppression on Zeb1 by GRHL2 resulted in the irreversibility of MET $(95,103)$. Yet this irreversible MET has been proved to be unlocked by epigenetic modification in the preliminary experiment $(95,104)$. Future experimental work is still needed to uncover such mechanisms comprehensively.

\section{PERSPECTIVE}

EMT is a highly dynamic process involved in not only the metastatic cascade, but also several hallmarks of cancer, such as cancer cell stemness, therapy resistance, and immune evasion (5). These pleiotropic functions represent great therapeutic windows to reduce the risk of recurrence and enhance the efficacy of conventional chemotherapy or immunotherapy. However, many problems warrant further investigation (1). Although mounting evidence has indicated that instead of a binary process between epithelial and mesenchymal states, EMT represents different intermediate states, the specific contextdependent regulatory mechanisms underlying such partial states remain to be determined (2). To date, although emerging studies have demonstrated the existence of intermediate EMT in vivo using lineage-tracing strategies (9), most of which concerning the role of epigenetic mechanisms in EMT were conducted in cancer cells in vitro, and were merely restricted to the interaction between EMT-TFs and epigenetic regulators. To what extent do epigenetic modifications contribute to these hybrid states in vivo, especially during the distinct steps of the metastatic cascade, is still poorly understood. To address these two problems, future studies must take into consideration of the functional redundancy of EMT triggers and pathways and highly heterogeneous contexts across different cancer types (3). Moreover, the advance in techniques might help establish a clearer epigenetic-EMT network. At present, most studies employ epithelial markers such as EPCAM to isolate CTCs, which may yield confounding results due to the existence of partial EMT. Thus, the establishment of novel assays depending on the physical distinctions between CTCs and normal cells in the circulatory system will greatly facilitate the identification of precise and dynamic EMT of CTCs (105). From a therapeutic standpoint, many epigenetic reagents tested in current studies hold tremendous potential against cancer metastatic, further research is required to elucidate the underlying mechanisms by which epigenetic drugs regulate cell states transition via EMT modulation $(4,5)$ Given the complex and multifacet features of EMP, it has to be leveraged with spatiotemporal precision for therapy development, for instance, an EMT-MET map would help characterize the landscape of cells undergoing EMT/MET of 
tumor samples (92), thus facilitating selection of appropriate therapeutic targets.

\section{AUTHOR CONTRIBUTIONS}

$\mathrm{H}-\mathrm{NC}$ and Z-GZ designed the article. Q-LL performed the literature search. Q-LL and ML drafted the work. H-NC and $\mathrm{CH}$ revised the work. All authors contributed to the article and approved the submitted version.

\section{REFERENCES}

1. Valastyan S, Weinberg RA. Tumor Metastasis: Molecular Insights and Evolving Paradigms. Cell (2011) 147(2):275-92. doi: 10.1016/ j.cell.2011.09.024

2. Obenauf AC, Massague J. Surviving at a Distance: Organ-Specific Metastasis. Trends Cancer (2015) 1(1):76-91. doi: 10.1016/j.trecan. 2015.07.009

3. Lamouille S, Xu J, Derynck R. Molecular Mechanisms of EpithelialMesenchymal Transition. Nat Rev Mol Cell Biol (2014) 15(3):178-96. doi: 10.1038/nrm3758

4. Brabletz T. To Differentiate or Not-Routes Towards Metastasis. Nat Rev Cancer (2012) 12(6):425-36. doi: 10.1038/nrc3265

5. Nieto MA, Huang RY, Jackson RA, Thiery JP. Emt: 2016. Cell (2016) 166 (1):21-45. doi: 10.1016/j.cell.2016.06.028

6. Lu W, Kang Y. Epithelial-Mesenchymal Plasticity in Cancer Progression and Metastasis. Dev Cell (2019) 49(3):361-74. doi: 10.1016/j.devcel.2019.04.010

7. Klymkowsky MW, Savagner P. Epithelial-Mesenchymal Transition: A Cancer Researcher's Conceptual Friend and Foe. Am J Pathol (2009) 174 (5):1588-93. doi: 10.2353/ajpath.2009.080545

8. Trimboli AJ, Fukino K, de Bruin A, Wei G, Shen L, Tanner SM, et al. Direct Evidence for Epithelial-Mesenchymal Transitions in Breast Cancer. Cancer Res (2008) 68(3):937-45. doi: 10.1158/0008-5472.CAN-07-2148

9. Pastushenko I, Brisebarre A, Sifrim A, Fioramonti M, Revenco T, Boumahdi $\mathrm{S}$, et al. Identification of the Tumour Transition States Occurring During EMT. Nature (2018) 556(7702):463-+. doi: 10.1038/s41586-018-0040-3

10. Beerling E, Seinstra D, de Wit E, Kester L, van der Velden D, Maynard C, et al. Plasticity Between Epithelial and Mesenchymal States Unlinks EMT From Metastasis-Enhancing Stem Cell Capacity. Cell Rep (2016) 14 (10):2281-8. doi: 10.1016/j.celrep.2016.02.034

11. Zheng X, Carstens JL, Kim J, Scheible M, Kaye J, Sugimoto H, et al. Epithelial-to-Mesenchymal Transition is Dispensable for Metastasis But Induces Chemoresistance in Pancreatic Cancer. Nature (2015) 527 (7579):525-30. doi: 10.1038/nature16064

12. Krebs AM, Mitschke J, Losada ML, Schmalhofer O, Boerries M, Busch H, et al. The EMT-activator Zeb1 is a Key Factor for Cell Plasticity and Promotes Metastasis in Pancreatic Cancer. Nat Cell Biol (2017) 19(5):518+. doi: 10.1038/ncb3513

13. Burger GA, Danen EHJ, Beltman JB. Deciphering Epithelial-Mesenchymal Transition Regulatory Networks in Cancer Through Computational Approaches. Front Oncol (2017) 7:162. doi: 10.3389/fonc.2017.00162

14. Grigore AD, Jolly MK, Jia D, Farach-Carson MC, Levine H. Tumor Budding: The Name is EMT. Partial EMT. J Clin Med (2016) 5(5):51. doi: 10.3390/ jcm5050051

15. Yang J, Antin P, Berx G, Blanpain C, Brabletz T, Bronner M, et al. Guidelines and Definitions for Research on Epithelial-Mesenchymal Transition. Nat Rev Mol Cell Biol (2020) 21(6):341-52. doi: 10.1038/s41580-020-0237-9

16. Ye X, Weinberg RA. Epithelial-Mesenchymal Plasticity: A Central Regulator of Cancer Progression. Trends Cell Biol (2015) 25(11):675-86. doi: 10.1016/ j.tcb.2015.07.012

17. Wei SC, Yang J. Forcing Through Tumor Metastasis: The Interplay Between Tissue Rigidity and Epithelial-Mesenchymal Transition. Trends Cell Biol (2016) 26(2):111-20. doi: 10.1016/j.tcb.2015.09.009

\section{FUNDING}

This work was supported by (1) National Natural Science Foundation of China (81702378, 82073246, and 81821002); (2) China Postdoctoral Science Foundation (2019T120845, 2018M643496); (3) Sichuan Science and Technology Program (2019YFS0263); (4) Post-Doctor Research Project, West China Hospital, Sichuan University (19XJ0075, 2018HXBH007); and (5) 1.3.5 project for disciplines of excellence, West China Hospital, Sichuan University (2016105).

18. Williams ED, Gao D, Redfern A, Thompson EW. Controversies Around Epithelial-Mesenchymal Plasticity in Cancer Metastasis. Nat Rev Cancer (2019) 19(12):716-32. doi: 10.1038/s41568-019-0213-x

19. Jolly MK, Somarelli JA, Sheth M, Biddle A, Tripathi SC, Armstrong AJ, et al. Hybrid Epithelial/Mesenchymal Phenotypes Promote Metastasis and Therapy Resistance Across Carcinomas. Pharmacol Ther (2019) 194:16184. doi: 10.1016/j.pharmthera.2018.09.007

20. Mittal V. Epithelial Mesenchymal Transition in Tumor Metastasis. Annu Rev Pathol (2018) 13:395-412. doi: 10.1146/annurev-pathol-020117-043854

21. Samatov TR, Tonevitsky AG, Schumacher U. Epithelial-Mesenchymal Transition: Focus on Metastatic Cascade, Alternative Splicing, non-Coding RNAs and Modulating Compounds. Mol Cancer (2013) 12(1):107. doi: 10.1186/1476-4598-12-107

22. Skrypek N, Goossens S, De Smedt E, Vandamme N, Berx G. Epithelial-toMesenchymal Transition: Epigenetic Reprogramming Driving Cellular Plasticity. Trends Genet (2017) 33(12):943-59. doi: 10.1016/j.tig.2017.08.004

23. Si WZ, Huang W, Zheng Y, Yang Y, Liu XJ, Shan L, et al. Dysfunction of the Reciprocal Feedback Loop Between GATA3-and Zeb2-Nucleated Repression Programs Contributes to Breast Cancer Metastasis. Cancer Cell (2015) 27(6):822-36. doi: 10.1016/j.ccell.2015.04.011

24. Lin YW, Wu YD, Li JL, Dong CF, Ye XF, Chi YI, et al. The SNAG Domain of Snaill Functions as a Molecular Hook for Recruiting LysineSpecific Demethylase 1. EMBO J (2010) 29(11):1803-16. doi: 10.1038/ emboj. 2010.63

25. Fukagawa A, Ishii H, Miyazawa K, Saitoh M. deltaEF1 Associates With DNMT1 and Maintains DNA Methylation of the E-cadherin Promoter in Breast Cancer Cells. Cancer Med (2015) 4(1):125-35. doi: $10.1002 /$ cam 4.347

26. Li L, Liu J, Xue H, Li C, Liu Q, Zhou Y, et al. A TGF-beta-MTA1-SOX4EZH2 Signaling Axis Drives Epithelial-Mesenchymal Transition in Tumor Metastasis. Oncogene (2020) 39(10):2125-39. doi: 10.1038/s41388019-1132-8

27. Cho MH, Park JH, Choi HJ, Park MK, Won HY, Park YJ, et al. DOT1L Cooperates With the c-Myc-p300 Complex to Epigenetically Derepress CDH1 Transcription Factors in Breast Cancer Progression. Nat Commun (2015) 6:7821. doi: 10.1038/ncomms8821

28. Monteiro-Reis S, Lameirinhas A, Miranda-Goncalves V, Felizardo D, Dias PC, Oliveira J, et al. Sirtuins' Deregulation in Bladder Cancer: SIRT7 is Implicated in Tumor Progression Through Epithelial to Mesenchymal Transition Promotion. Cancers (Basel) (2020) 12(5):1066. doi: 10.3390/ cancers12051066

29. Yang MH, Hsu DSS, Wang HW, Wang HJ, Lan HY, Yang WH, et al. Bmil is Essential in Twist1-induced Epithelial-Mesenchymal Transition. Nat Cell Biol (2010) 12(10):982-92. doi: 10.1038/ncb2099

30. Wang W, Friedland SC, Guo B, O’Dell MR, Alexander WB, Whitney-Miller CL, et al. ARID1A, a SWI/SNF Subunit, is Critical to Acinar Cell Homeostasis and Regeneration and is a Barrier to Transformation and Epithelial-Mesenchymal Transition in the Pancreas. Gut (2019) 68(7):124558. doi: 10.1136/gutjnl-2017-315541

31. Cardenas H, Vieth E, Lee J, Segar M, Liu Y, Nephew KP, et al. TGF-Beta Induces Global Changes in DNA Methylation During the Epithelial-toMesenchymal Transition in Ovarian Cancer Cells. Epigenetics-Us (2014) 9 (11):1461-72. doi: 10.4161/15592294.2014.971608 
32. McDonald OG, Wu H, Timp W, Doi A, Feinberg AP. Genome-Scale Epigenetic Reprogramming During Epithelial-to-Mesenchymal Transition. Nat Struct Mol Biol (2011) 18(8):867-74. doi: 10.1038/nsmb.2084

33. Yuan S, Natesan R, Sanchez-Rivera FJ, Li J, Bhanu NV, Yamazoe T, et al. Global Regulation of the Histone Mark H3K36me2 Underlies Epithelial Plasticity and Metastatic Progression. Cancer Discovery (2020) 10(6):854-71. doi: 10.1158/2159-8290.CD-19-1299

34. Pastushenko I, Mauri F, Song Y, de Cock F, Meeusen B, Swedlund B, et al. Fat1 Deletion Promotes Hybrid EMT State, Tumour Stemness and Metastasis. Nature (2021) 589(7842):448-55. doi: 10.1038/s41586-02003046-1

35. Siemens H, Jackstadt R, Hunten S, Kaller M, Menssen A, Gotz U, et al. miR34 and SNAIL Form a Double-Negative Feedback Loop to Regulate Epithelial-Mesenchymal Transitions. Cell Cycle (2011) 10(24):4256-71. doi: $10.4161 /$ cc. 10.24 .18552

36. Davalos V, Moutinho C, Villanueva A, Boque R, Silva P, Carneiro F, et al. Dynamic Epigenetic Regulation of the microRNA-200 Family Mediates Epithelial and Mesenchymal Transitions in Human Tumorigenesis. Oncogene (2012) 31(16):2062-74. doi: 10.1038/onc.2011.383

37. Bendoraite A, Knouf EC, Garg KS, Parkin RK, Kroh EM, O’Briant KC, et al. Regulation of miR-200 Family microRNAs and ZEB Transcription Factors in Ovarian Cancer: Evidence Supporting a Mesothelial-to-Epithelial Transition. Gynecol Oncol (2010) 116(1):117-25. doi: 10.1016/j.ygyno. 2009.08.009

38. Snowdon J, Zhang X, Childs T, Tron VA, Feilotter H. The microRNA-200 Family is Upregulated in Endometrial Carcinoma. PloS One (2011) 6(8): e22828. doi: 10.1371 /journal.pone.0022828

39. Fantozzi A, Gruber DC, Pisarsky L, Heck C, Kunita A, Yilmaz M, et al. VEGF-Mediated Angiogenesis Links EMT-induced Cancer Stemness to Tumor Initiation. Cancer Res (2014) 74(5):1566-75. doi: 10.1158/00085472.CAN-13-1641

40. Ota I, Li XY, Hu Y, Weiss SJ. Induction of a MT1-MMP and MT2-MMPdependent Basement Membrane Transmigration Program in Cancer Cells by Snail1. Proc Natl Acad Sci U S A (2009) 106(48):20318-23. doi: 10.1073/ pnas.0910962106

41. Juncker-Jensen A, Deryugina EI, Rimann I, Zajac E, Kupriyanova TA, Engelholm LH, et al. Tumor MMP-1 Activates Endothelial PAR1 to Facilitate Vascular Intravasation and Metastatic Dissemination. Cancer Res (2013) 73(14):4196-211. doi: 10.1158/0008-5472.CAN-12-4495

42. Chabottaux V, Ricaud S, Host L, Blacher S, Paye A, Thiry M, et al. Membrane-Type 4 Matrix Metalloproteinase (MT4-MMP) Induces Lung Metastasis by Alteration of Primary Breast Tumour Vascular Architecture. J Cell Mol Med (2009) 13(9B):4002-13. doi: 10.1111/j.15824934.2009.00764.x

43. Friedl P, Mayor R. Tuning Collective Cell Migration by Cell-Cell Junction Regulation. Cold Spring Harb Perspect Biol (2017) 9(4):a029199. doi: 10.1101/cshperspect.a029199

44. Aceto N, Bardia A, Miyamoto DT, Donaldson MC, Wittner BS, Spencer JA, et al. Circulating Tumor Cell Clusters are Oligoclonal Precursors of Breast Cancer Metastasis. Cell (2014) 158(5):1110-22. doi: 10.1016/ j.cell.2014.07.013

45. Padmanaban V, Krol I, Suhail Y, Szczerba BM, Aceto N, Bader JS, et al. ECadherin is Required for Metastasis in Multiple Models of Breast Cancer. Nature (2019) 573(7774):439-44. doi: 10.1038/s41586-019-1526-3

46. Yu M, Bardia A, Wittner BS, Stott SL, Smas ME, Ting DT, et al. Circulating Breast Tumor Cells Exhibit Dynamic Changes in Epithelial and Mesenchymal Composition. Science (2013) 339(6119):580-4. doi: 10.1126/ science. 1228522

47. Wang W, Wan L, Wu S, Yang J, Zhou Y, Liu F, et al. Mesenchymal Marker and LGR5 Expression Levels in Circulating Tumor Cells Correlate With Colorectal Cancer Prognosis. Cell Oncol (Dordr) (2018) 41(5):495-504. doi: 10.1007/s13402-018-0386-4

48. Fumagalli A, Oost KC, Kester L, Morgner J, Bornes L, Bruens L, et al. Plasticity of Lgr5-Negative Cancer Cells Drives Metastasis in Colorectal Cancer. Cell Stem Cell (2020) 26(4):569-78.e7. doi: 10.1016/j.stem. 2020.02.008

49. Liu X, Li J, Cadilha BL, Markota A, Voigt C, Huang Z, et al. Epithelial-Type Systemic Breast Carcinoma Cells With a Restricted Mesenchymal Transition are a Major Source of Metastasis. Sci Adv (2019) 5(6):eaav4275. doi: 10.1126/ sciadv.aav 4275

50. Campbell K, Rossi F, Adams J, Pitsidianaki I, Barriga FM, Garcia-Gerique L, et al. Collective Cell Migration and Metastases Induced by an Epithelial-toMesenchymal Transition in Drosophila Intestinal Tumors. Nat Commun (2019) 10(1):2311. doi: 10.1038/s41467-019-10269-y

51. Stoletov K, Kato H, Zardouzian E, Kelber J, Yang J, Shattil S, et al. Visualizing Extravasation Dynamics of Metastatic Tumor Cells. J Cell Sci (2010) 123(Pt 13):2332-41. doi: 10.1242/jcs.069443

52. Frose J, Chen MB, Hebron KE, Reinhardt F, Hajal C, Zijlstra A, et al. Epithelial-Mesenchymal Transition Induces Podocalyxin to Promote Extravasation Via Ezrin Signaling. Cell Rep (2018) 24(4):962-72. doi: 10.1016/j.celrep.2018.06.092

53. Celia-Terrassa T, Bastian C, Liu DD, Ell B, Aiello NM, Wei Y, et al. Hysteresis Control of Epithelial-Mesenchymal Transition Dynamics Conveys a Distinct Program With Enhanced Metastatic Ability. Nat Commun (2018) 9(1):5005. doi: 10.1038/s41467-018-07538-7

54. Pixberg CF, Raba K, Muller F, Behrens B, Honisch E, Niederacher D, et al. Analysis of DNA Methylation in Single Circulating Tumor Cells. Oncogene (2017) 36(23):3223-31. doi: 10.1038/onc.2016.480

55. Riethdorf S. Detection of microRNAs in Circulating Tumor Cells. Transl Cancer Res (2018) 7:S197-208. doi: 10.21037/tcr.2017.10.24

56. Leblanc R, Peyruchaud O. Metastasis: New Functional Implications of Platelets and Megakaryocytes. Blood (2016) 128(1):24-31. doi: 10.1182/ blood-2016-01-636399

57. Wang K, Ji W, Yu Y, Li Z, Niu X, Xia W, et al. Fgfr1-ERK1/2-SOX2 Axis Promotes Cell Proliferation, Epithelial-Mesenchymal Transition, and Metastasis in FGFR1-amplified Lung Cancer. Oncogene (2018) 37 (39):5340-54. doi: 10.1038/s41388-018-0311-3

58. Li W, Zhang Z, Liu X, Cheng X, Zhang Y, Han X, et al. The FOXN3-NEAT1SIN3A Repressor Complex Promotes Progression of Hormonally Responsive Breast Cancer. J Clin Invest (2017) 127(9):3421-40. doi: 10.1172/JCI94233

59. Yin X, Zhang BH, Zheng SS, Gao DM, Qiu SJ, Wu WZ, et al. Coexpression of Gene Oct4 and Nanog Initiates Stem Cell Characteristics in Hepatocellular Carcinoma and Promotes Epithelial-Mesenchymal Transition Through Activation of Stat3/Snail Signaling. J Hematol Oncol (2015) 8:23. doi: 10.1186/s13045-015-0119-3

60. Gkountela S, Castro-Giner F, Szczerba BM, Vetter M, Landin J, Scherrer R, et al. Circulating Tumor Cell Clustering Shapes DNA Methylation to Enable Metastasis Seeding. Cell (2019) 176(1-2):98-112.e14. doi: 10.1016/ j.cell.2018.11.046

61. Ortiz V, Yu M. Analyzing Circulating Tumor Cells One at a Time. Trends Cell Biol (2018) 28(10):764-75. doi: 10.1016/j.tcb.2018.05.004

62. Vega S, Morales AV, Ocana OH, Valdes F, Fabregat I, Nieto MA. Snail Blocks the Cell Cycle and Confers Resistance to Cell Death. Genes Dev (2004) 18(10):1131-43. doi: 10.1101/gad.294104

63. Park JH, Sung IJ, Lee SW, Kim KW, Kim YS, Yoo MA. The Zinc-Finger Transcription Factor Snail Downregulates Proliferating Cell Nuclear Antigen Expression in Colorectal Carcinoma Cells. Int J Oncol (2005) 26 (6):1541-7.

64. Esposito M, Mondal N, Greco TM, Wei Y, Spadazzi C, Lin SC, et al. Bone Vascular Niche E-selectin Induces Mesenchymal-Epithelial Transition and Wnt Activation in Cancer Cells to Promote Bone Metastasis. Nat Cell Biol (2019) 21(5):627-39. doi: 10.1038/s41556-019-0309-2

65. Del Pozo Martin Y, Park D, Ramachandran A, Ombrato L, Calvo F, Chakravarty P, et al. Mesenchymal Cancer Cell-Stroma Crosstalk Promotes Niche Activation, Epithelial Reversion, and Metastatic Colonization. Cell Rep (2015) 13(11):2456-69. doi: 10.1016/j.celrep.2015.11.025

66. Gao D, Joshi N, Choi H, Ryu S, Hahn M, Catena R, et al. Myeloid Progenitor Cells in the Premetastatic Lung Promote Metastases by Inducing Mesenchymal to Epithelial Transition. Cancer Res (2012) 72(6):1384-94. doi: 10.1158/0008-5472.CAN-11-2905

67. Chaffer CL, Brennan JP, Slavin JL, Blick T, Thompson EW, Williams ED. Mesenchymal-to-Epithelial Transition Facilitates Bladder Cancer Metastasis: Role of Fibroblast Growth Factor Receptor-2. Cancer Res (2006) 66(23):11271-8. doi: 10.1158/0008-5472.CAN-06-2044

68. Tsai JH, Donaher JL, Murphy DA, Chau S, Yang J. Spatiotemporal Regulation of Epithelial-Mesenchymal Transition Is Essential for 
Squamous Cell Carcinoma Metastasis. Cancer Cell (2012) 22(6):725-36. doi: 10.1016/j.ccr.2012.09.022

69. Eichelberger L, Saini M, Moreno HD, Klein C, Bartsch JM, Falcone M, et al. Maintenance of Epithelial Traits and Resistance to Mesenchymal Reprogramming Promote Proliferation in Metastatic Breast Cancer. bioRxiv [Preprint] (2020). doi: 10.1101/2020.03.19.998823

70. Jia D, Jolly MK, Kulkarni P, Levine H. Phenotypic Plasticity and Cell Fate Decisions in Cancer: Insights From Dynamical Systems Theory. Cancers (Basel) (2017) 9(7):70. doi: 10.20944/preprints201705.0129.v1

71. Jia D, Jolly MK, Tripathi SC, Den Hollander P, Huang B, Lu M, et al. Distinguishing Mechanisms Underlying EMT Tristability. Cancer Converg (2017) 1(1):2. doi: 10.1186/s41236-017-0005-8

72. Li C, Hong T, Nie Q. Quantifying the Landscape and Kinetic Paths for Epithelial-Mesenchymal Transition From a Core Circuit. Phys Chem Chem Phys (2016) 18(27):17949-56. doi: 10.1039/C6CP03174A

73. Hur K, Toiyama Y, Takahashi M, Balaguer F, Nagasaka T, Koike J, et al. MicroRNA-200c Modulates Epithelial-to-Mesenchymal Transition (EMT) in Human Colorectal Cancer Metastasis. Gut (2013) 62(9):1315-26. doi: 10.1136/gutjnl-2011-301846

74. Taube JH, Sphyris N, Johnson KS, Reisenauer KN, Nesbit TA, Joseph R, et al. The H3K27me3-demethylase KDM6A is Suppressed in Breast Cancer StemLike Cells, and Enables the Resolution of Bivalency During the Mesenchymal-Epithelial Transition. Oncotarget (2017) 8(39):65548-65. doi: 10.18632/oncotarget.19214

75. Chen HN, Shu Y, Liao F, Liao X, Zhang H, Qin Y, et al. Genomic Evolution and Diverse Models of Systemic Metastases in Colorectal Cancer. Gut (2021) gutjnl-2020-323703. doi: 10.1136/gutjnl-2020-323703

76. Chikarmane SA, Tirumani SH, Howard SA, Jagannathan JP, DiPiro PJ. Metastatic Patterns of Breast Cancer Subtypes: What Radiologists Should Know in the Era of Personalized Cancer Medicine. Clin Radiol (2015) 70 (1):1-10. doi: 10.1016/j.crad.2014.08.015

77. Dongre A, Weinberg RA. New Insights Into the Mechanisms of EpithelialMesenchymal Transition and Implications for Cancer. Nat Rev Mol Cell Bio (2019) 20(2):69-84. doi: 10.1038/s41580-018-0080-4

78. Beg MS, Brenner AJ, Sachdev J, Borad M, Kang YK, Stoudemire J, et al. Phase I Study of MRX34, a Liposomal miR-34a Mimic, Administered Twice Weekly in Patients With Advanced Solid Tumors. Invest New Drugs (2017) 35(2):180-8. doi: 10.1007/s10637-016-0407-y

79. van Zandwijk N, Pavlakis N, Kao SC, Linton A, Boyer MJ, Clarke S, et al. Safety and Activity of microRNA-loaded Minicells in Patients With Recurrent Malignant Pleural Mesothelioma: A First-in-Man, Phase 1, Open-Label, Dose-Escalation Study. Lancet Oncol (2017) 18(10):1386-96. doi: 10.1016/S1470-2045(17)30621-6

80. Bhatia S, Monkman J, Toh AKL, Nagaraj SH, Thompson EW. Targeting Epithelial-Mesenchymal Plasticity in Cancer: Clinical and Preclinical Advances in Therapy and Monitoring. Biochem J (2017) 474(19):3269306. doi: 10.1042/BCJ20160782

81. Takeuchi S, Hase T, Shimizu S, Ando M, Hata A, Murakami H, et al. Phase I Study of Vorinostat With Gefitinib in BIM Deletion Polymorphism/ Epidermal Growth Factor Receptor Mutation Double-Positive Lung Cancer. Cancer Sci (2020) 111(2):561-70. doi: 10.1111/cas.14260

82. Gordon SW, McGuire WP,3, Shafer DA, Sterling RK, Lee HM, Matherly SC, et al. Phase I Study of Sorafenib and Vorinostat in Advanced Hepatocellular Carcinoma. Am J Clin Oncol (2019) 42(8):649-54. doi: 10.1097/ COC. 0000000000000567

83. Fischer KR, Durrans A, Lee S, Sheng J, Li F, Wong ST, et al. Epithelial-toMesenchymal Transition is Not Required for Lung Metastasis But Contributes to Chemoresistance. Nature (2015) 527(7579):472-6. doi: 10.1038 /nature 15748

84. Puhr M, Hoefer J, Schafer G, Erb HHH, Oh SJ, Klocker H, et al. Epithelial-to-Mesenchymal Transition Leads to Docetaxel Resistance in Prostate Cancer and Is Mediated by Reduced Expression of miR-200c and Mir-205. Am J Pathol (2012) 181(6):2188-201. doi: 10.1016/j.ajpath. 2012.08.011

85. Li Y, VandenBoom TG,2, Kong D, Wang Z, Ali S, Philip PA, et al. Up-Regulation of miR-200 and Let-7 by Natural Agents Leads to the Reversal of Epithelial-to-Mesenchymal Transition in Gemcitabine-
Resistant Pancreatic Cancer Cells. Cancer Res (2009) 69(16):6704-12. doi: 10.1158/0008-5472.CAN-09-1298

86. Ji M, Lee EJ, Kim KB, Kim Y, Sung R, Lee SJ, et al. HDAC Inhibitors Induce Epithelial-Mesenchymal Transition in Colon Carcinoma Cells. Oncol Rep (2015) 33(5):2299-308. doi: 10.3892/or.2015.3879

87. Feng J, Cen J, Li J, Zhao R, Zhu C, Wang Z, et al. Histone Deacetylase Inhibitor Valproic Acid (VPA) Promotes the Epithelial Mesenchymal Transition of Colorectal Cancer Cells Via Up Regulation of Snail. Cell Adh Migr (2015) 9(6):495-501. doi: 10.1080/19336918.2015.1112486

88. Cardenas H, Zhao J, Vieth E, Nephew KP, Matei D. EZH2 Inhibition Promotes Epithelial-to-Mesenchymal Transition in Ovarian Cancer Cells. Oncotarget (2016) 7(51):84453-67. doi: 10.18632/oncotarget.11497

89. Li Z, Xiao C, Yong T, Li Z, Gan L, Yang X. Influence of Nanomedicine Mechanical Properties on Tumor Targeting Delivery. Chem Soc Rev (2020) 49(8):2273-90. doi: 10.1039/C9CS00575G

90. Hari K, Sabuwala B, Subramani BV, La Porta CAM, Zapperi S, Font-Clos F, et al. Identifying Inhibitors of Epithelial-Mesenchymal Plasticity Using a Network Topology-Based Approach. NPJ Syst Biol Appl (2020) 6(1):15. doi: 10.1038/s41540-020-0132-1

91. Ishay-Ronen D, Diepenbruck M, Kalathur RKR, Sugiyama N, Tiede S, Ivanek R, et al. Gain Fat-Lose Metastasis: Converting Invasive Breast Cancer Cells Into Adipocytes Inhibits Cancer Metastasis. Cancer Cell (2019) 35(1):17-+. doi: 10.1016/j.ccell.2018.12.002

92. Karacosta LG, Anchang B, Ignatiadis N, Kimmey SC, Benson JA, Shrager JB, et al. Mapping Lung Cancer Epithelial-Mesenchymal Transition States and Trajectories With Single-Cell Resolution. Nat Commun (2019) 10(1):5587. doi: 10.1038/s41467-019-13441-6

93. Stylianou N, Lehman ML, Wang C, Fard AT, Rockstroh A, Fazli L, et al. A Molecular Portrait of Epithelial-Mesenchymal Plasticity in Prostate Cancer Associated With Clinical Outcome. Oncogene (2019) 38(7):913-34. doi: 10.1038/s41388-018-0488-5

94. Katsuno Y, Meyer DS, Zhang Z, Shokat KM, Akhurst RJ, Miyazono K, et al. Chronic TGF-beta Exposure Drives Stabilized EMT, Tumor Stemness, and Cancer Drug Resistance With Vulnerability to Bitopic mTOR Inhibition. Sci Signal (2019) 12(570):eaau8544. doi: 10.1126/scisignal.aau8544

95. Jia W, Deshmukh A, Mani SA, Jolly MK, Levine H. A Possible Role for Epigenetic Feedback Regulation in the Dynamics of the EpithelialMesenchymal Transition (EMT). Phys Biol (2019) 16(6):066004. doi: 10.1088/1478-3975/ab34df

96. Gregory PA, Bracken CP, Smith E, Bert AG, Wright JA, Roslan S, et al. An Autocrine TGF-beta/ZEB/miR-200 Signaling Network Regulates Establishment and Maintenance of Epithelial-Mesenchymal Transition. Mol Biol Cell (2011) 22(10):1686-98. doi: 10.1091/mbc.e11-02-0103

97. Tian XJ, Zhang H, Xing J. Coupled Reversible and Irreversible Bistable Switches Underlying TGFbeta-induced Epithelial to Mesenchymal Transition. Biophys J (2013) 105(4):1079-89. doi: 10.1016/j.bpj.2013.07.011

98. Zhang J, Tian XJ, Zhang H, Teng Y, Li R, Bai F, et al. TGF-Beta-Induced Epithelial-to-Mesenchymal Transition Proceeds Through Stepwise Activation of Multiple Feedback Loops. Sci Signal (2014) 7(345):ra91. doi: 10.1126/scisignal.2005304

99. Watanabe K, Panchy N, Noguchi S, Suzuki H, Hong T. Combinatorial Perturbation Analysis Reveals Divergent Regulations of Mesenchymal Genes During Epithelial-to-Mesenchymal Transition. NPJ Syst Biol Appl (2019) 5:21. doi: 10.1038/s41540-019-0097-0

100. Serresi M, Kertalli S, Li L, Schmitt MJ, Dramaretska Y, Wierikx J, et al. Functional Antagonism of Chromatin Modulators Regulates EpithelialMesenchymal Transition. Sci Adv (2021) 7(9):eabd7974. doi: 10.1126/ sciadv.abd7974

101. Brown MS, Abdollahi B, Wilkins OM, Chakraborty P, Ognjenovic NB, Muller KE, et al. Dynamic Plasticity Within the EMT Spectrum, Rather Than Static Mesenchymal Traits, Drives Tumor Heterogeneity and Metastatic Progression of Breast Cancers. bioRxiv [Preprint] (2021). doi: 10.1101/ 2021.03.17.434993

102. Johnson KS, Hussein S, Song S, Chakraborty P, Jolly MK, Toneff MJ, et al. Gene Expression and Chromatin Accessibility During Progressive EMT and MET Linked to Dynamic CTCF Engagement. bioRxiv [Preprint] (2020). doi: $10.1101 / 2020.05 .11 .089110$ 
103. Jia W, Tripathi S, Chakraborty P, Chedere A, Rangarajan A, Levine H, et al. Epigenetic Feedback and Stochastic Partitioning During Cell Division can Drive Resistance to EMT. Oncotarget (2020) 11(27):2611-24. doi: 10.18632/ oncotarget.27651

104. Somarelli JA, Shetler S, Jolly MK, Wang X, Bartholf Dewitt S, Hish AJ, et al. Mesenchymal-Epithelial Transition in Sarcomas is Controlled by the Combinatorial Expression of MicroRNA 200s and GRHL2. Mol Cell Biol (2016) 36(19):2503-13. doi: 10.1128/MCB.00373-16

105. Keller L, Pantel K. Unravelling Tumour Heterogeneity by Single-Cell Profiling of Circulating Tumour Cells. Nat Rev Cancer (2019) 19(10):55367. doi: 10.1038/s41568-019-0180-2
Conflict of Interest: The authors declare that the research was conducted in the absence of any commercial or financial relationships that could be construed as a potential conflict of interest.

Copyright () $2021 \mathrm{Liu}$, Luo, Huang, Chen and Zhou. This is an open-access article distributed under the terms of the Creative Commons Attribution License (CC BY). The use, distribution or reproduction in other forums is permitted, provided the original author(s) and the copyright owner(s) are credited and that the original publication in this journal is cited, in accordance with accepted academic practice. No use, distribution or reproduction is permitted which does not comply with these terms. 